\title{
Responsabilidad Subjetiva en la Guerra. Caso Colombia
}

\author{
José Alexander Herrera Contreras ${ }^{1}$
}

\begin{abstract}
Resumen
Objetivo. Realizar un ejercicio de reflexión teórica, alrededor del concepto de la responsabilidad subjetiva, pensado en el escenario de la guerra.
\end{abstract}

Método. Utilizando la metodología de la narrativa, se realizó un recorrido por los acontecimientos que han soportado el origen y desarrollo del conflicto. Posteriormente, el artículo muestra el recorrido del concepto de subjetividad, en diferentes momentos y con distintos autores, para establecer en cual sentido es comprendido el referente teórico. En el campo del psicoanálisis, se retomaron algunos autores que han indagado por el concepto de responsabilidad subjetiva.

Resultados. Se presenta un diálogo entre los autores y algunos fragmentos de entrevistas realizadas a estudiantes en condición de desmovilización y reinserción del conflicto armado en Colombia, bajo el rol de estudiantes de la UNAD.

Palabras clave: responsabilidad subjetiva, conflicto, decisión, acuerdos de paz, desmovilización. 


\title{
Subjective responsibility in the war. Colombian case
}

\begin{abstract}
Objective. Develop an exercise of theoretical reflection around the concept of subjective responsibility, thinking about the war context.

Method. Using the methodology of narrative, a journey was made by the events that have supported the origin and development of the conflict. Subsequently, the article shows the path of the concept of subjectivity, at different times and with different authors, to establish in which direction is understood the theoretical reference. In the field of psychoanalysis, some authors have investigated the concept of subjective responsibility resumed.
\end{abstract}

Results. A dialogue between authors and excerpts from interviews with students on condition of demobilization and reintegration of armed conflict in Colombia, presented in the role of students of UNAD.

Keywords: Subjective responsibility, conflict, decision, agreement of the peace, demobilization.

Recibido: 10-05-2015

Aceptado: 11-06-2015

Si revisamos las posibilidades creativas de la guerra, son pocas...de tal suerte que lo único que cabe es la repetición...

de tomas, ataques, emboscadas, voladuras, sabotajes.... la diferencia está, en la razón o no, en el propósito, el manejo, el contenido político o el contexto (Grave, 2000). 


\section{Introducción}

El presente artículo tiene como propósito generar diálogo, a partir de la instalación de la pregunta sobre la categoría de la responsabilidad subjetiva, en el escenario de la guerra, en excombatientes de los grupos armados guerrilleros y paramilitares en Colombia.

Así entonces, la apuesta escrita surge a partir de la investigación "Resignificando la paz, una experiencia educativa con los estudiantes reinsertados de la UNAD"2, realizada por el grupo de investigación Cuchavira, vinculado a la Universidad Nacional Abierta y a Distancia UNAD.

De esta manera, durante el desarrollo del proyecto se ha logró identificar el surgimiento de categorías como educación, territorialidad, y decisión; en relación con la categoría de la decisión por la vía armada o por la desvinculación del conflicto, abrió el camino para reflexionar alrededor del sujeto que tomó la decisión, por las armas, por la muerte, en el escenario de la guerra.

Con relación a lo anterior, el desarrollo de este artículo, no sólo encara la posibilidad de agenciar nuevas formas de pensar y encontrar salidas al conflicto, que distan de las condiciones anteriores en los cuales han sido llevados a cabo los procesos de paz, y que como resultado han finalizado en el fracaso de los mismos, transitados desde la inmediatez y el asistencialismo estatal, sino que abarca desde el reconocimiento de la responsabilidad política que debe recaer sobre los actores involucrados, hasta la responsabilidad subjetiva en todos los excombatientes. Así mismo, señala un aporte teórico en el análisis del conflicto armado en Colombia y de qué manera decantar la categoría de la responsabilidad subjetiva; orientará acciones, decisiones y comprensiones distintas frente al escenario bélico, contribuyendo en el discernimiento entre el sujeto y su vínculo con la guerra, que conlleva a establecer una singularidad, una subjetividad, una responsabilidad en este fenómeno.

Por otra parte, la revisión bibliográfica se agota en el punto de concebir al sujeto de la responsabilidad subjetiva, en el escenario de la guerra, como un sujeto atravesado por el lenguaje y, por consiguiente, subjetivamente responsable; más allá de asumir a ese sujeto que ha tomado una decisión en medio de unas condiciones y circunstancias particulares, violentas y resistentes, interesa también concebirlo como un sujeto no alienado por un discurso, ideología, o institución, que cuenta con el poder de la palabra, y que está determinado con relación a el lugar que ha asumido desde su deseo, desde la Ley, y en relación con el Otro. 
De otro modo, las nuevas circunstancias políticas, económicas y sociales, que se han venido tejiendo en forma paralela con el devenir histórico de la guerra, han marcado la pauta en la necesidad de insistir en una visión que trasgreda la comprensión del conflicto, como un acto que representa la violencia, o como un síntoma social contemporáneo, y que hagan que se cree un horizonte diferente en la comprensión del fenómeno armado. Desde estas consideraciones, el marco teórico que soporta esta puesta en palabras, ha sido pensado en tres momentos: un primer momento concierne a una revisión de los antecedentes y condiciones en los cuales surgieron los grupos de guerrillas y paramilitares en Colombia. También se mencionan algunos eventos históricos en los que han sido efectuados procesos de paz, evidenciando las falencias que estos han tenido. En un segundo momento, se realiza un recorrido por el concepto de subjetividad, con el propósito de precisar el referente teórico y el sentido en que será utilizado. Finalmente se hace un acercamiento a la noción de responsabilidad subjetiva, como categoría de análisis y construcción teórica.

\section{Metodología}

El problema que orientó la investigación daba respuesta a la reflexión del cómo la educación, pensada en forma de un dispositivo de inclusión, debe ser reflexionada desde lo profundo de las dimensiones de la subjetividad, intersubjetividades y nuevas formas de subjetivación que encaran las exigencias del regreso a la vida civil, en escenarios de conflicto y postconflicto. Para tal fin se diseñaron talleres y entrevistas, que determinaban una ruta histórica de cada estudiante, en condición de desmovilización o reinserción, y se implementaron por medio de grupos focales.

El análisis de la información recolectada se hizo a través de una matriz de análisis construida para tal propósito, en donde se logro develar las narrativas colocadas allí. En este marco de acción, la implementación de la metodología narrativa resultó ser la opción más acertada. Lugo y Pinilla (2007); "Desde esta perspectiva se entiende que las construcciones que hacen los sujetos frente a situaciones históricas y vivenciadas por ellos permite identificar categorías de análisis y da orientaciones metodológicas para interpretar el mundo desde la interacción, los valores, percepciones de actores sociales y cómo estos, construyen los significados sociales" (Caro y Gómez, 2011).

Finalmente, la metodología desde el análisis de las narrativas, posibilitó comprender los textos surgidos de las entrevistas y talleres "La narrativa es algo más que la simple configuración de relatos; es también un vehículo para la comprensión e interpretación de las personificaciones, entre las relaciones entre los sujetos y de sentidos contextualizados en el tiempo y en el espacio" (Lara 2010). 


\section{Construcción teórica}

\section{*Del conflicto.}

El conflicto armado en Colombia ha sido uno de los procesos bélicos más complejos en Latinoamérica, no sólo por sus consecuencias inmediatas: crisis humanitaria, desplazamiento forzado, exilio, entre otras, sino también, por su larga duración. "Quien recorre este interminable teatro de los combates de ayer, encuentra a cada paso, y en una confusión sin igual, indecibles desesperaciones y todo género de miserias" (Dunant 1982).

Algunas apuestas han señalado que los grupos guerrilleros surgen de una coyuntura histórica, política y social, no adecuada, en el transcurso de la década comprendida entre 1960 - 1970. En esa época se conformarían la mayoría de grupos armados al margen de la ley, mediatizados por tres elementos, que para ese momento conspiraban puntualmente para tal fin. Por consiguiente, el escenario y las condiciones estaban dadas, la Revolución cubana, la legitimación de una propuesta Socialista a través de la U.R.S.S., y el desencantamiento hacia el Estado colombiano, por parte de los ciudadanos, está última soportada desde la acción movilizada por agresión militar, persecución a los líderes políticos liberales, el sin sabor del asesinato de Jorge Eliécer Gaitán (1948) y la constante desigualdad social que operaba en las zonas rurales.

En relación con el surgimiento de las guerrillas, Sánchez (1999), afirma que: "El Ejército de Liberación Popular nació públicamente a las armas y a la guerra a comienzos de 1967 en una región del departamento de Córdoba llamada Llanos del Tigre”. En atención a los hallazgos encontrados, vehiculizados por las investigaciones realizadas que han indagado por los factores políticos que auspiciaron la vida armada, se ha encontrado que una gran fuerza política, (el movimiento campesino, el movimiento estudiantil, el movimiento sindical) comprendida ésta como una ideología emancipatoria, respaldaba el proyecto armado para ese momento; cabe señalar que los grupos de guerrillas iniciaron como agrupaciones de autodefensas campesinas, y que en Colombia la organización sindical operó a partir de 1920, registrándose un acontecimiento trascendental en la historia del país: la masacre de las bananeras, ocurrida en 1930, que se convirtió en un hecho que determinaría nuevas acciones de resistencia civil.

En ese contexto, "los núcleos guerrilleros iniciales en Colombia (1962-1973), tanto como los que se frustraron, tal es el caso del Movimiento Obrero Estudiantil Campesino MOEC o las Fuerzas Armadas de Liberación F.A.L., como los que lograron consolidarse como el Ejército de Liberación Nacional, Ejército Popular de Liberación Nacional, nacieron imbuidos de una mentalidad foquista ${ }^{3}$. La única excepción fueron las FARC debido a sus hondas raíces societales, en las regiones de tradición comunista" (Pizarro, 1990). 
Sumado a lo anterior, la aparición de los movimientos guerrilleros surgió en dos escenarios de distinta constitución, toda vez que la conformación de los primeros grupos de guerrillas era respaldada desde una justificación de diferente orden, con relación a la segunda generación que daría origen a nuevos grupos guerrilleros. Por lo que "dada la extrema debilidad organizativa del polo popular, éste no era un actor constituido, de manera que la guerrilla sólo lograba representar intereses sociales locales. Esta nueva etapa estaría signada por la emergencia del Quintín Lame, Movimiento Independiente Revolucionario, Partido Revolucionario de Trabajadores, la consolidación del M-19 de los guerrilleros de la segunda generación cuyos métodos, perspectivas y lenguajes conducirían a una subversión de la subversión, es decir, a una renovación del movimiento insurgente. Esta renovación coincide con un fenómeno nuevo en la vida nacional, cuyos gérmenes se daban en las luchas agrarias, estudiantiles y laborales de los años 70" (Pizarro, 1990).

Por otra parte, en relación con el surgimiento del proyecto paramilitar en Colombia, 1980 - 1990, el nacimiento de esta propuesta se consolidó a partir de tres factores decisivos. El primer factor daría respuesta a la fragilidad del Estado colombiano en hacer frente a las guerrillas y, por consiguiente, legitimar un poder público, que sólo es posible a través del ejercicio legal, es decir, Gobernabilidad. Como segundo factor, la respuesta de ganaderos, comerciantes y en general, personas con posibilidades económicas favorables, que ante las frecuentes extorsiones, actos violentos, etc., por parte de los grupos guerrilleros, decidieron contratar grupos de seguridad privada; esto señalaba el pago de salarios, a cambio de seguridad.

Finalmente, el factor decisivo que no sólo permitió la consolidación de los grupos paramilitares como una estructura política, económica y militar, altamente blindada y puesta sobre el andamiaje social, sino además, la infiltración del paramilitarismo por medio de la legitimación de los servidores públicos y su confabulación con las Fuerzas Armadas, se hizo evidente con el apoyo de las Fuerzas Militares y algunos congresistas. Así entonces, se dio la bienvenida al surgimiento del paramilitarismo en Colombia; y propició que "el haber perdido el Estado el monopolio de la violencia, otros actores tales como entidades étnicas, bandas criminales, guerrillas, etc., serán los protagonistas de la guerra" (Fojón, 2006).

En relación con lo anterior, se registran las siguientes apreciaciones: "El Estado no consigue consolidar su presencia territorial, ni el monopolio de las armas, ni la recuperación de la justicia, ni actúa con suficiente legitimidad. En medio de la impunidad, proliferó el paramilitarismo, con apoyo o permisividad oficial; generalmente asociado, de manera estructural, al narcotráfico y a otras formas de economía legal e ilegal, en alianza con sectores terratenientes, ganaderos y de poderes locales y de políticos tradicionales, lo cual ha ocasionado una actuación genocida contra la población" (Villarraga, 2006). 
Así entonces, el panorama bélico ha sido agenciado por distintas causas que transitan desde una clara ausencia institucional, la trasgresión de límites en relación con las lógicas puestas en la guerra, pasando por la desconfiguración de la estructura social, hasta la búsqueda de respuestas inmediatas que rayan con la perversión e indiferencia frente al conflicto. Entre los factores psicosociales, el factor de la venganza se observa como uno de los más influyentes, "la venganza, la descomposición familiar, la sensación de poder que dan las armas, son razones poderosas que pueden empujar a un joven campesino a meterse a grupos guerrilleros o grupos paramilitares" (Lepri, 2004).

Bajo la lógica de dar fin al conflicto, varios han sido los esfuerzos por parte de los distintos gobiernos que le han apostado a propuestas de paz y acuerdos negociados. El rastreo histórico muestra que desde 1953, en el gobierno del General Gustavo Rojas Pinilla, este declaró la amnistía para los grupos alzados en armas, y para la fuerza pública; esta sería la manera como la mayoría de guerrillas liberales se desmovilizaron en ese tiempo. Durante los años sesenta, el Presidente Alberto Lleras Camargo aplicó la amnistía para los guerrilleros y represión para los bandoleros; sin embargo, debido a presiones por parte de bancadas conservadoras, prefirió finalmente el procedimiento represivo. En el marco del Plan Nacional de Rehabilitación, en el año de 1982, el Presidente Belisario Betancourt logró aprobar la Ley 35 de Amnistía General, dirigida a los grupos de guerrillas que se mantenían vigentes para ese momento.

Continuando, a fines de los ochenta, el entonces Presidente, Virgilio Barco, a través de una propuesta de paz conocida como "Iniciativa de Paz", consiguió dar inicio al proceso de desmovilización del M-19, que culminó en 1990 con la desmovilización de 800 personas pertenecientes a este grupo armado. A partir de allí, en 1991, el PRT se desmovilizó, así como el EPL y el Quintín Lame. Posteriormente, en 1994, un sector del ELN concertó un acuerdo de paz. Y es entonces cuando, legitimado por el Decreto 1385, surge un mecanismo legal para posibilitar otorgar indultos individuales y participar en los programas de reinserción. Bajo este Decreto, entre 1994 y 2002, cerca de 2.000 combatientes que hacían parte de los grupos armados FARC y ELN entregaron sus armas.

El Observatorio de Procesos de Desarme, Desmovilización y Reintegración de la Universidad Nacional de Colombia registró que "entre 1990 - 1998 se desmovilizaron 4.775 combatientes pertenecientes a diez organizaciones guerrilleras" (OPDDR, 2012b).

En relación con los procesos de desmovilización de los grupos paramilitares, regulados por la Ley de Justicia y Paz, promovida por el entonces Presidente Álvaro Uribe Vélez, se otorgaron beneficios jurídicos, económicos y políticos a cerca de 20.000 combatientes pertenecientes a grupos paramilitares, que se desmovilizaron entre el 2002 y 2008. "Según lo reportado por la Oficina del Alto Comisionado para la Paz, durante el periodo comprendido entre 2002 - 2011 
se han desmovilizado colectivamente 31.810 personas, de las cuales 31.656 pertenecen a grupos paramilitares, 105 a las FARC y 49 al ERG” (OPDDR, 2012a).

Desde un orden nacional, el resultado de las graves crisis humanitarias, la degradación de los métodos usados por grupos paramilitares y guerrilleros, el reforzamiento de la política represiva a líderes campesinos, indígenas y obreros, por parte del Estado, el desplazamiento y los miles de víctimas que ha dejado a su paso la guerra en Colombia, sumado a los frustrados y fallidos procesos y/o acuerdos de paz que se han instalado bajo la presión política y económica del gobierno de turno, han dado como resultado que más de un millar de desmovilizados hayan sido asesinados, no haya cesado la violación de los Derechos Humanos, a tal punto que se han configurado expresiones de genocidio en contra de la población civil; además, orientados por la necesidad de mostrar resultados, se han legitimado políticas de exterminio en contra de los actores sociales, develando la participación de militares en crímenes de Estado.

Siguiendo varios de los desmovilizados, tanto de grupos guerrilleros como paramilitares, han optado por el retorno a la vida armada, constituyendo nuevas formas de violencia, a través de bandas criminales o enfilándose nuevamente en otros grupos al margen de la ley. La manipulación mediática que actúa básicamente en las masas de las ciudades principales ha generado las condiciones necesarias para el sostenimiento de una guerra, favorable para varios sectores, e indiferente para los actores que no participan directamente de la misma, en los escenarios en donde se libran tan demenciales batallas.

La guerra es un punto de encuentro de la condición humana. En ese sentido, la guerra ha sostenido el andamiaje del lazo social y es así como cada sociedad produce los sujetos que necesita enlistar en la guerra; de igual forma, por el escenario bélico transitan los síntomas sociales, hechos reales en el conflicto armado colombiano. La guerra se piensa desde la trasgresión, desde el combate, es una guerra de resistencias en el tiempo, más que de accionar militar.

En Colombia se ha consolidado una guerra de emociones, de intereses hostiles, de la muerte del otro en lo simbólico y en lo real, de encuentros y desencuentros, de la desinstalación de una estructura subjetiva, de la trasgresión de toda ley y la recreación de la perversión. Según Clausewitz (2002), "El propósito político es el objetivo, mientras que la guerra es el medio y el medio no puede ser nunca considerado separadamente del objetivo".

Desde este breve recorrido por los avatares del conflicto armado colombiano, se puede aproximar una conclusión, ayer como hoy "es dudoso que la Fuerza Pública tenga éxito en el corto plazo para afirmar su control en todo el territorio. Sus recursos financieros no le permiten multiplicar las operaciones a gran escala. Difícilmente podrán prescindir de la cooperación de los paramilitares 
que, aunque se desmovilizaron parcialmente, bien podrían asegurar unas tareas de vigilancia sobre la población; de ahora en adelante el conflicto entra más bien en una fase de aceleración y de todas partes hay una carrera de velocidad. Las guerrillas tienen el interés de adelantarse al reforzamiento de las Fuerzas Armadas; éstas, a su vez, están obligadas a mostrar resultados para mantener el apoyo de la opinión. Los paramilitares deben mimetizarse en el paisaje y reconocer sus abusos si quieren convertirse en una fuerza política.

En este panorama, Estados Unidos está preocupado por los efectos del conflicto en los países vecinos, aún así es poco probable que en el plano propiamente militar se produzca un cambio rápido" (Pécaut, 2003).

\section{*Sujeto, subjetividad y travesía histórica}

A partir de una revisión histórica es posible identificar que el desarrollo conceptual asociado al concepto de sujeto y subjetividad, se ha identificado en cuatro grandes momentos: El pensamiento clásico griego y su adecuación en la escolástica; la emergencia del pensamiento moderno, los pensadores de la sospecha y por último el pensamiento posmoderno.

\section{El pensamiento clásico griego y su adecuación en la escolástica.}

En el pensamiento Griego la subjetividad no existe como concepto ya que el sujeto es el eje de la reflexión, la cual se orienta a una característica frente a la relación esencia - existencia: "El subjectum es lo sub-puesto, lo sub-yecto en el actus, algo a lo que también puede recaerle otra cosa, en esto que le recae es el accidens; en este sentido, lo subyecto, lo subyacente asume el papel de fundamento sobre el que se pone otra cosa" (Heidegger, 2000, p. 344). Estos términos se relacionan con lo que constituye al "ente" en su verdadero ser, en la medida en que lo subjectum es aquello que perdura, es lo constante, y de ese modo, es lo que está debajo de todo: la substantia (Heidegger, 2000, p. 345). Es importante identificar que desde la perspectiva antigua, el subjectum era lo que estaba "por debajo", como fundamento (esencia) de la existencia, que se da en la realidad efectiva.

Con el advenimiento del pensamiento judeo-cristiano, la idea se orienta a la transformación de los conceptos e ideas últimas de la reflexión; sin embargo, la estructura del ejercicio argumentativo sigue los criterios de tipo Clásico, es decir, el subjectum, se reduce a la presencia-esencia divina, como una apuesta que convocaba la pregunta por la existencia del alma, asociada necesariamente a la existencia de una entidad externa de tipo todopoderosa, eterna y "subjectum" de la existencia humana. El Renacimiento del pensamiento Griego, y la búsqueda de sus orígenes posibilita un segundo giro en el recorrido de las reflexiones sobre la subjetividad, producto de la declarada confrontación de muchos pensadores con el poder y la autoridad de la iglesia y motivados por las reflexiones que se 
generaban en campos tan diversos como la física, la matemática y la literatura, emerge así una re-lectura de la subjetividad.

\section{La emergencia del pensamiento moderno}

Según Burger \& Burger (2001), en Montaigne, las acciones humanas son influenciadas por condiciones azarosas y es aquí donde se da una clara ruptura con el pensamiento desarrollado por los pensadores medievales, ruptura con el ser supremo, el sujeto no orienta sus acciones bajo la influencia divina, tanto acciones como pensamientos invocan una pregunta existencial, pero que diferiría posteriormente con Descartes, en la modernidad, porque éste, plantea la idea de un sujeto desde la razón, "cogito" que en la época moderna inscribiría el saber científico como la vía para alcanzar la plena armonía de hombre en libertad y al hombre como un ser de control, autoregulado, que soslayaba en cualquier cuestión de azar e incertidumbre. Sin embargo, Pascal en clara discrepancia con el sujeto de Descartes, reclama y demanda por el hombre y su existencia dando lugar a la pérdida, entendida como el vacío, el sujeto escindido entre su voluntad y su racionalidad presenta la posibilidad de repensar el sujeto en su necesidad de ser en el mundo.

Voltaire, emitiendo su discurso desde la ilustración, intenta rescatar el sentido por la vida; con gran certeza propone que el hombre debe sobrepasar los peligros que lo asechan "La tesis positivista de Voltaire, es que la condición humana con todas sus debilidades y peligros tiene sentido y es digna de ser vivida, al margen de cualquier conexión con amenazas y promesas de dudosos dominios trascendentales" (Alonso, 2004, p. 87).

No menos importantes para la modernidad, tres filósofos que retoma Burger \& Burger (2001), son Baudelaire, quien propone para su época un yo que se construye en el hombre mismo, fracturando así el discurso que legitimaba un Dios organizador de la vida y Flaubert quien plantea la necesidad de pensar al hombre de la modernidad como un ser atravesado por su deseo de crecimiento personal, el cual busca distintas formas de satisfacción, como estrategia para mitigar su existir y Rousseau precisamente, vendrá a incorporar la dialéctica en que se encuentra el sujeto, entre su voluntad y racionalidad. Parte de considerar que el sujeto moderno está siempre en búsqueda de la verdad, no como un problema gnoseológico, sino como un problema existencial; así, la certeza del yo no es ya la universalidad de la razón, sino la inconfundible especificidad del individuo. Es decir que este autor viene a reivindicar al sujeto como sujeto, en su individualidad y complejidad. Acá cabe resaltarlo, surge constantemente la pregunta por la subjetividad orientada por la pregunta en torno a un devenir existencial.

\section{Los pensadores de la sospecha}

Jean Paul Sartre aparece como el finalizador del discurso moderno y su relación con la subjetividad. Este autor construye una teoría dentro de la tradición 
cartesiana que se fundamenta entre la separación del mundo del objeto y el de la conciencia; así pues, propone que el yo auténtico es el yo que renuncia a su conciencia. Desde esta lógica Sartre analiza el comportamiento al establecer que el sentimiento de auto valía del yo lo constituye la capacidad de repudiarse así mismo, "El yo no está en la conciencia, ni es idéntico a ella. El yo está afuera....en el mundo como cualquier otro", (Alonso, 2004, p. 71). Sartre, al pensar la conciencia separada del yo, muestra en el sujeto postmoderno la capacidad de imaginar un mundo de modo distinto, en donde la conciencia no está sujeta a leyes de casualidad sino que opera a través de la necesidad de ser en el mundo; finalmente es una pregunta por la vida, formulada desde un sentido existencialista, que, se instala en los sujetos del tiempo de Sartre como la paradoja que se refiere a "como ser en el mundo".

Además, de este breve recorrido se puede establecer cómo el discurso de cada autor estuvo mediatizado por el contexto cultural de la época en que se inscribía; así, los diferentes teóricos que asumieron la pregunta por el sujeto, pasando por el sujeto racional de Descartes, hasta Rosseau que, encuentra en el sujeto moderno, un sujeto no racional, sin voluntad e inscrito en la pregunta por su existencia, nos muestra claramente hasta donde se habla de sujeto y cuando se viene a hablar de subjetividad, es decir, desaparece el sujeto racional y nace el sujeto de la experiencia, experiencia que se estructura a partir de los procesos de subjetivación que operan y configuran al sujeto en su momento histórico.

\section{Los modos y formas de subjetivación en la postmodernidad}

Es necesario señalar que el espíritu moderno, en su afán por alcanzar la verdad, olvidó que es inalcanzable y soslayó que ese saber que se erigía como verdad, dejaría a los sujetos vacíos de poiesis una vez que se alcanzara. Es precisamente desde esta situación como se concibe la postmodernidad: “(...) la época en la que el hombre ya no se entusiasma por un futuro que encanta, prometido para antes o para después de la muerte", según Pommier (2002, p. 9). El sujeto postmoderno encarna la creencia de que ya no hay nada más que ofrecer, ni que le ofrezcan, así, los autores de esta época postmoderna construirían teoría a partir de un sujeto que no está destinado a adquirir un saber que le asegure una plena armonía en el mundo, sino que se trata de un sujeto que está atravesado por el horror de su inexistencia, de su propia subjetividad.

En este sentido, uno de los autores más significativos y revolucionarios para su época, debido a su aporte teórico con relación a la constitución de la psique humana y su nueva mirada hacia el sujeto, seria Sigmund Freud; el hombre está regido por una fuerza que lo constituye y determina su comportamiento y sufrimiento, el inconsciente: sería el concepto teórico más importante con el que se asociaría el nuevo sujeto del siglo XX. Además Freud, a través de su obra construiría nuevas categorías de análisis que contribuirían al desarrollo de una teoría que aportaría elementos conceptuales para explicar la subjetividad que plantea González: "Con el psicoanálisis apareció el primer intento de 
explicar los fenómenos psíquicos de la personalidad, constituida por diferentes formas y expresiones sociales del sujeto, si bien para ser significativas, desde la perspectiva psicoanalítica, estas experiencias tenían que ser de naturaleza sexual" (González, 1999, p. 145).

Orientado por el pensamiento freudiano, así como por el estructuralismo de Levi Strauss, el francés J. Lacan presenta una teoría del sujeto en un dominio esencialmente simbólico. Para el autor según Nasio, el lenguaje precede al sujeto y lo estructura: "El sujeto se construye a partir del lenguaje" (1997, p. 88). El sujeto lacaniano constituido en el lenguaje y por el lenguaje, es un sujeto vacío que estará gobernado por su falta ${ }^{4}$ de ser en el mundo, un sujeto sin capacidad de realización, un sujeto escindido. Para este autor el sujeto está suspendido, encadenado al mundo de los significantes, que serán estos mismos los que han de orientar sus actos. Entre los aportes más relevantes del autor con relación a la teoría de la subjetividad contemporánea, es la estrecha articulación que opera en el lenguaje como estructura simbólica en la configuración del sujeto.

Desde esta corriente epistemológica y disciplinaria, Elliot opone resistencia al sujeto lacaniano, (influenciado por el materialismo histórico) y rompe la concepción que se tenía del sujeto y su dramática relación con la psique, en su complejidad y estructura, señalando la integración dialéctica de lo social en la dimensión constitutiva del sujeto, estableciendo de esta manera, una nueva instancia en el tema de la subjetividad.

Retomando la influencia de lo social en la constitución del sujeto, para Marx el hombre aparece en una situación social que lo alinea de su producción y resquebraja la imagen de que el esfuerzo personal lleva a un desarrollo personal creciente. Marx muestra fuerzas sociales ocultas que conspiran contra el crecimiento humano, y desde una postura dialéctica de la subjetividad, L.S. Vygotsky y S.L Rubinstein comprenden el proceso individual y social como momentos dentro de la organización de la psique humana. La superación de la dicotomía entre lo individual y social por parte de estos autores, facilitó una representación del hombre como ser articulado, y en ese sentido, la psique humana como proceso subjetivo: "la dimensión social no se mantiene como hecho externo con respecto al hombre, ella penetra y desde dentro determina su conciencia" (González, 1999, p. 200).

De otro lado, Vygostky dirigió sus esfuerzos al estudio del desarrollo de la conciencia para explicar la subjetividad. Su concepto de interiorización se fundamentaba en el significado como unidad en la actividad psíquica del sujeto; este significado se entendió como un proceso en el cual el hombre establecía nuevas adquisiciones internas en su desarrollo psíquico, forjadas a través de los procesos sociales. Este rompe la dicotomía en la que se encontraba el sujeto, abriendo así la puerta a nuevas teorías subjetivistas. 
Orientados por esta misma cosmovisión marxista, Castoriadis y Guatari realizan su trabajo en el contexto de un referente psicoanalítico, criticando las premisas universales freudianas y lacanianas, donde el concepto de subjetividad entraría en una significación abierta, dialéctica, dialógica y compleja; Castoriadis comprende al sujeto en los diversos procesos sociales, culturales e históricos, intentando articular y conceptualizar la realidad social e individual en un proceso de tipo subjetivo, postulando una teoría social, donde el tema de la subjetividad se instala como su principal referente, toda vez que parte del concepto de lo imaginario como producción subjetiva.

En relación con lo imaginario, Castoriadis establece el concepto de praxis como una categoría organizadora de la realidad social, la cual viene a operar en un sentido construccionista de la acción humana, es decir: "la praxis en Castoriadis es un concepto orientado a la legitimación de la procesualidad, la parcialidad y el cambio, tanto en la definición de los procesos de la vida social y psíquica como en los procesos de su conocimiento" (González, 1999, p. 60).

De la cita anterior se puede apreciar la importancia que Castoriadis confiere al orden social en su dimensión compleja y organizadora, identificando el sentido como una categoría que actúa en un sistema dialéctico y múltiple, configurándose en contextos únicos en donde el sujeto es participante y portador de sentidos, así pues, la articulación conceptual que se logra establecer entre estas dos categorías, imaginario y sentido, es que la existencia de lo imaginario posibilita formas de organización simbólica en el complejo tejido social. Vemos entonces en Castoriadis una pretendida teoría social-subjetiva de fuerte connotación estructurante, en donde el sujeto, se convierte en el facilitador del pacto social, y en este sentido, en el garante de la construcción subjetiva de cada sociedad.

Por su parte, F. Guattari concibe la subjetividad como una producción social, en donde la singularización del sujeto se rompe y entra a hacer parte de la formación perfectamente organizada de la subjetividad gobernante, es decir, el sujeto se debate en estrategias de control y de poder que se instala de manera inconsciente en los sujetos y hacen de estos productos el consumo de masas. Sin embargo, este autor propone que los sujetos vehiculizan diferentes procesos de cambio, movilizados por el deseo, entendido éste como un proceso en permanente producción, es decir, el sujeto no sólo es constituido sino que también es constituyente de su realidad, y en ese sentido no sólo asumirá un lugar de sujeto disciplinado sino además, un lugar desde la resistencia.

Guattari marca nuevos rumbos en la subjetividad contemporánea, al realizar el anclaje entre las prácticas sociales y los sujetos inmersos en dichas prácticas. Esta visión procesal rompe sin lugar a dudas con el hermetismo del sujeto freudiano, representándolo en un nivel más complejo y contradictorio, en donde la construcción subjetiva de la realidad, se encuentra en constante desarrollo y presente en los momentos, temporales e históricos del sujeto y de su espacio social. 
Por último y desde la sociología, Touraine vendrá a desmitificar de cierta manera el determinismo que Guattari le asigna al orden social y en este intento recuperará al sujeto concibiéndolo como su actor principal, más no como su efecto. Este plantea que el sistema social no debe ser visto como agente omnipotente, sino como un orden determinado único y exclusivamente por los sujetos. Así, su teoría le apuesta al sujeto de la emancipación, nuevo orden social, soportado en un sujeto constituido subjetivamente y con capacidad de subjetivar nuevas prácticas sociales; el sujeto reorganiza nuevas prácticas través de su capacidad de ruptura y de opción creativa: dialéctica recursiva, que simultáneamente, se configura en la acción del pacto social con el otro.

Unido al concepto de sujeto, la subjetivación, como el proceso de "ser" sujeto lleva a trasladar el concepto de individuo, para reconocer un sujeto siempre en transición, mediado como lo plantea Díaz (2005), por vínculos no coercitivos y dialógicos. Es fundamental reconocer la importancia que desde diversas áreas del saber se le concede actualmente a la dimensión cultural, a los nuevos órdenes sociales globales que se están configurando, donde Muñoz (2007), considera que se redefine un espacio tiempo, configurado en términos de una biografía propia.

A su vez, fundamental es el reconocer que el sentido histórico-social de lo subjetivo, retomando el concepto de "enteridad", citado por Alvarado (2005), evoluciona como "el reconocimiento de esos múltiples yo-es que habitan a su vez múltiples condiciones identitarias, en colectivos desregulados (nosotros), que se corresponden mucho más con una realidad diversa, vital y compleja, de sujetos impermanentes, transformados, conflictivos e imperfectos", y que lleva a pensarse desde la modernidad como un pensamiento constitutivo de la época y posmodernidad, como el lugar vacío dejado por el sujeto.

Es por ello que las subjetivaciones, como parte del ser, resultan ser los modos de verse y sentirse en el mundo, de insertarse en él, las tendencias actuales que se orientan a construir las relaciones a través de lo afectivo, de la sensibilidad social y la capacidad de representarse en el mundo; estos modos de ser, están relacionados con la posibilidad en otras palabras, de la conciencia de ser.

Las relaciones de poder vigentes, de Foucault, para Díaz (2005), estarían inmersas en lo institucional, cobrarían un sentido de lo estético y lo político a través de la negociación, producto y reflexión de un disenso y es allí donde los múltiples discursos se configuran y constituyen para cobrar sentido de ser y estar y para co-construir la realidad que se devela en la narración; cuestión que en otras palabras habla de lo intersubjetivo, mencionado antes, que es la posibilidad de reconocerse en el disenso, en la diferencia.

Vale mencionar como Alvarado (2005), configuraría a través de diversas esferas constituyentes de los procesos de subjetivación, el sentido de la diferencia y más allá, el potencial de lo humano como "evento psicosocial". Por una parte 
el potencial afectivo, por otra, el potencial creativo, entendido como el uso de la razón, del pensamiento, de la capacidad de generar ideas, las alternativas dialógicas y el potencial ético-moral, de lo intersubjetivo como constructo humano.

Las dinámicas de subjetividad que se co-crean en una contingencia cultural y bajo múltiples paradigmas de lo social, se reflejan actualmente, bajo el pensamiento de autores como Deleuze (1995), citado por Muñoz (2007: 71), quien señala que "los procesos de subjetivación (...) sólo valen la pena en la medida en que al realizarse, escapan de los poderes dominantes. Aunque ellos [los sujetos] mismos se prolonguen en nuevos poderes... tienen en su momento una espontaneidad rebelde". Aquí, las condiciones para la civilidad, no serán producto de un ejercicio de poder, serán el resultado de una experiencia que se negocia en el escenario público y privado.

Así, las acciones que reconfiguran un ser en lo social y en lo cultural, se medían a través de los roles, de los estatus, de las lógicas de la identidad, desde las prácticas relatadas, y que para Muñoz (2007), más que alojar sujetos específicos, efectivamente, los crea, toman sentido, significan el ser y sentirse parte en la construcción de escenarios y el poder; develar discursos, generar los espacios de diálogos de saberes y simbolizar la realidad, esto también implica mirar un sujeto que se recrea en el discurso de su interlocutor, de otro modo, que lo político signifique en lo público, diversas interpretaciones de los principios que orientan la vida... el poder es constituido pero no constituye sujetos, formas de ser sujetos mediados por modos de subjetivación. El discurso político es una forma de ser sujeto, se es sujeto cuando se reconoce a través de ese discurso creado; así, el consenso, como la expresión de lo fáctico, y el sujeto en el marco del conflicto armado, como parte de los fenómenos sociales co-creados, estará marcado por la configuración de realidades que aparecen en la vida social, al mismo tiempo que se amplían sus marcos incluyentes, según lo plantea Chaparro (2005), considerando la relación asincrónica mediada por la violencia.

\section{De la responsabilidad subjetiva en la guerra.}

Con referentes teóricos y fragmentos de entrevistas realizadas a estudiantes en condición de desmovilización y/o reinserción del conflicto, se ofrece al lector una aproximación a la categoría teórica que orienta esta reflexión escrita.

El sujeto en psicoanálisis es pensado como un sujeto sujetado, sujetado a una cultura, a un lenguaje inconsciente. Es un sujeto castrado, desde y por el lenguaje, que mediatiza sus formas de relación frente al lugar que asume desde la ley, desde el Otro. Por consiguiente, reflexionar alrededor del sujeto en la guerra, es tramitar un sujeto vinculado desde y por su subjetividad. "Se trata de la destitución de la razón. La verdad del sujeto está en otra parte; remite a la 
estructura de su deseo que lo constituye y lo organiza en su relación con la ley, la cultura, lo simbólico" (Díaz, 2002). El sujeto del cual damos cuenta, es el sujeto que reconoce la ley y su transgresión, en caso contrario, hablaríamos de un sujeto desde una estructura perversa.

La decisión por la vía armada, recaba en los motivos colectivos que alimentaban el acto, mas no se identifica algún intento de tejido subjetivo, que rescate al sujeto en su singularidad.

\begin{abstract}
¿Qué significaba ingresar para usted a un grupo armado? ¿Por qué tomó la decisión de ingresar también a ese grupo armado? bueno pues heeee prácticamente yo desde niña era una zona roja, allá la guerrilla estaba todo el tiempo y por allá las cosas marchaban bien todo, prácticamente ellos mandaban en todo, no había delincuencia, ladrones no había nada de eso, y pues ellos desde ese tiempo ellos van sembrando una ideología, y pues uno cree en eso,... de creer que puede haber una Colombia como mejor... Estudiante 1 / Ibagué - Tolima -

Colombia. Noviembre, 2012.
\end{abstract}

Para el caso, los discursos ideológicos han venido emergiendo como dispositivos de subjetivación, en donde no se abre paso a una aproximación por la individualidad, deslizando así, la dimensión subjetiva vinculada en el escenario bélico, hacia el amparo en el colectivo. "En la guerrilla opera una feroz normatividad y una des-responsabilización del sujeto. Esto podría nombrarse como 'suspensión subjetiva' o puesta entre paréntesis del sujeto, en tanto implica destituir al sujeto de su responsabilidad y, así mismo, la suspensión de su deseo, dando vía al goce. El sujeto subsume también en el colectivo su responsabilidad individual. Se emprende una cadena de actos de los cuales no es responsable, porque responde el colectivo a nombre del ideal" (Castro, 2001).

Soportado desde el lugar de comodidad que brinda una causa, el aniquilamiento, la destrucción, los actos de barbarie que rayan con la perversión y hasta la trasgresión de los límites, que antes se consideraban intocables, son suprimidos temporalmente, bajo la nueva lógica que demanda la vida en la guerra.

Como le manifesté al inicio, fue un paso mal dado, en el momento en que pienso dejar esa vida y retirarme ahi sí en mi vida sentí temor... cuando ya empezaron a surgir las famosas operaciones yo nunca habia participado en un combate... nunca, o sea... mm... asesinar a una persona... ahi es cuando yo digo esto no sirve, y pienso que si yo me retiro, qué tal que esta gente diga que yo soy un infiltrado y que estaba haciendo inteligencia, para ese momento ya los conocía a todos a los comandantes... Yo pensaba en mi familia y pensaba en mí... 
entonces eso fue lo que me llevó a no retirarme. Estudiante 2.

Cárcel La Picota. Bogotá-Colombia Septiembre, 2012.

En la puesta en escena de la confrontación armada, no hay mucho que pensar, al parecer, lo que emerge con certeza es una clara intención de sobrevivencia; sin embargo, allí mismo en donde la violencia muestra todo su poder, el amago por la subjetividad, la duda, la incertidumbre y hasta el miedo que es atisbado por el delito, serán luces de incomodidad y cuestionamientos por parte del sujeto, bajo la sombra de la clandestinidad. "En su esplendor, el narcisismo fulgurante del guerrero da lugar al valor y la osadía, protegiendo de la incertidumbre, del miedo, de la pregunta horadante. Tras esa investidura se resguarda el sujeto eludiendo su responsabilidad subjetiva y permitiéndose el despliegue del goce en el embeleso del poder" (Castro, 2002).

Ahora bien, se hace necesario establecer una aproximación a la diferencia entre culpa y responsabilidad. Por culpa se entiende una subjetivación de la ley, que se vincula desde un campo semántico de lo ético, religioso y moral. Con relación a la responsabilidad entra de lleno en el lugar de lo privado, de lo singular; no obstante, a la hora de su puesta en palabras, las dos han de tejerse en forma de un espiral. "No es posible una responsabilidad sin culpa y viceversa, y la inocencia no es más que la condición de una pertenencia basada en la complicidad, la culpa superyóica y la necesidad de expiación. La inocencia la da el pertenecer a una instancia redentora, la que sea" (Pereña, 2005).

¿De no haber existido el acuerdo de Paz con las Autodefensas, qué hubiera sucedido? J.J Yo creo que estaría muerto o preso, pero en otras condiciones, pero entonces no se tendría en cuenta las cosas que he hecho, como es la entrega voluntaria, confesar las cosas que yo hice... que yo hice no... que yo vi... pero que también participé... pero la verdad es que en mi contra no existía ningún proceso, pero todo lo que yo vi... todo lo que yo hice... se siente uno como traicionado por parte del Estado, al ver que quieran acabar con este proceso, no piensan en las víctimas... ese paso tan grande que se dio en la desmovilización para nada... entonces se siente uno como decepcionado por parte del Estado. Estudiante 2.

El deseo por la guerra, por la muerte, no es un deseo cualquiera... encara a un sujeto vinculado desde su goce ${ }^{5}$, que le permite tramitar un lugar distinto frente al otro del pacto social; desplaza la idea de la responsabilidad por un anhelo narcisista que justo se vislumbra en el imaginario, y se perpetúa en lo que desea que del Otro le sea reconocido.

Para mí ingresar a las autodefensas en un primer momento significó volver a recuperar mi dignidad... de que tenía una 
fuerza, de que ya era alguien, tenía un fusil, inclusive tuve la oportunidad de tener un fusil, pero a mi toda la vida me ha gustado el trabajo con las comunidades, a la gente, entonces usted me puede servir a mi no en la parte militar sino en la parte de la organización, y entonces a mí me dio esa fuerza de sobrevivencia preliminarmente. Estudiante 3. Centro Penitenciario La Picota. Bogotá - Colombia. Octubre, 2012.

Como es visible, la noción de responsabilidad subjetiva que pretendo reflexionar, no responde a la culpa, por el contrario, incursiona en el sujeto que se hace cargo de lo que lo atraviesa en forma singular, de lo indecible en palabras, pero que es recreado en acto. "Freud se aleja de toda consideración de la enfermedad mental como algo que anula al sujeto de pleno derecho, y pone a éste en el primer plano bajo la forma de la responsabilidad subjetiva implicada en todo lo que él mismo desconoce de la determinación de sus actos" (Zawady, 2005).

Yo pienso que la decisión por la guerra es una decisión equivocada. Yo recuerdo que a las personas del pueblo que me decian que les gustaría hacer parte de ingresar a las autodefensas, yo les decía que lo pensaran... que por el hecho de verlo a uno en una moto o con una arma... i!!es una vida equivocada!!! Es una vida prestada. Estudiante 2.

La responsabilidad subjetiva a la que aludo, es la responsabilidad que implica al sujeto en su subjetividad, en su goce, en su castración. Más allá del acto jurídico que viene a sancionar otro-jurista, la responsabilidad debe ser sostenida desde la elección del sujeto; no supone que el sujeto tan solo es responsable de aquello de lo que logra responder desde su saber consciente; por el contrario, anuncia la paradoja en la que se encuentra el sujeto, al vincular su subjetividad en el escenario de la guerra. "La responsabilidad no concierne exclusivamente a la conciencia; el sujeto debe asumirla igualmente por lo inconsciente" (Jaramillo, 2005).

\section{Conclusión}

La noción sobre la categoría de responsabilidad subjetiva en la guerra de Colombia, implica pensar un sujeto que le apuesta al horror que se teja por medio de los hilos invisibles del goce, de una historia que en cada puntada señala una fractura, allí donde la palabra es remplazada por el acto violento. De igual manera rescata romper con el silencio y el olvido, de una guerra que ha sido legitimada a través de la indiferencia, que raramente nos cuestiona y que tan sólo nos sorprende cuando hacemos cuenta de la memoria.

La responsabilidad subjetiva en la guerra, para el caso colombiano, encara una aproximación de trascender al sujeto (guerrillero o paramilitar) por el sujeto del 
inconsciente, el sujeto escindido; implica una diferencia de la responsabilidad jurídica en donde entran en juego víctimas y victimarios y en donde el juego de la verdad es enunciado desde la lógica de la reparación, mas no de la verdad subjetiva, es decir, la verdad del deseo. "Hacer responsable al sujeto no es adecuarlo a lo que conoce o debiera conocer, es decir, a lo que desde un ordenamiento moral o jurídico se determina como deber, sino enfrentarlo con lo que no sabe de sí mismo, y es justo la causa de su hacer y su decir" (Chaves, 2005).

Así entonces, está reflexión teórica que presento a los lectores, traduce una pregunta frente al sujeto y su responsabilidad subjetiva en la guerra, elogia inevitablemente un lugar y un análisis parcial, matizado por la escucha de los actores implicados, y propone un diálogo ético, que conduzca a distinguir por las encrucijadas de la guerra, más no por los síntomas en que se produce y que reproduce. Desde estas consideraciones, se sugiere la revisión de una categoría teórica para ser colocada en escena y que señale una bitácora diversa, que nos permita orientar una perspectiva distinta de las causas y consecuencias del conflicto armado en Colombia, con el objetivo de comprender nuevas alternativas de salida, que disten de los sin sabores, silencios e indignación que en su andar ha instituido la misma. "Cada quien se adscribe al discurso de la guerra de un modo que trasciende su sometimiento, pues está comprometida una fabricación subjetiva que los implica en su responsabilidad" (Castro, 2005).

Desde estas consideraciones, resulta fundamental comprender a un sujeto desde su singularidad, y situarlo como un sujeto subjetivamente responsable, más allá de su vínculo con la masa, se trata de sostener el tránsito desde un lazo social a un lazo perverso, el sujeto de la responsabilidad subjetiva, se instituye allí en donde su decisión da cuenta de su deseo.

Con relación a las diferentes perspectivas que los actores tienen de la desmovilización y de su inserción a la vida social y la recuperación de las historias de vida de los estudiantes reinsertados de la UNAD, en aras de comprender las causas y motivos de su inserción en el escenario de la guerra y reinserción a la vida civil, los hallazgos metodológicos, permiten comprender que los lazos recuperados en lo territorial, develan reflexiones que asumen una distancia objetiva, mediada por la separación de la organización armada y como actor del conflicto, y que se asume otrora, a través de miradas institucionales y organizaciones nacientes; es decir, para los estudiantes desvinculados del conflicto, la nueva condición civil, señala una ruptura de significaciones que se constituyeron en el escenario de la guerra, anclado en un continuum de vida, y que ahora son insostenibles frente a la resignificación misma del acto bélico, porque se reconfigura la vida cotidiana y la condición del sujeto en un espacio tiempo del conflicto armado, sujeto de la acción dialógica (política) que reconfigura territorialidades, hacia la construcción de otras prácticas sociales. 
Finalmente, este artículo persigue la apuesta de resituar al sujeto combatiente desde un afuera del colectivo que lo representa y le brinda cuerpo, es abrir el escenario hacia la comprensión de un sujeto que legitima su goce mortífero a través de un ideal, una causa, una masa. "La causalidad psíquica que inaugura el discurso freudiano deja de lado, de esta manera, la pura exterioridad que antaño dominaba a la subjetividad e implica, por fin, al sujeto en su destino. No será, así, un mero resultado de una causalidad exterior que lo maneja sino que, desde la causalidad psíquica, está implicado en sus deseos, sus actos, y sus claudicaciones. Paradojas del descubrimiento freudiano, mientras proclama al sujeto del inconsciente al que le concierne por un lado un saber no sabido, asevera, al mismo tiempo, que hay una responsabilidad que cabe a ese sujeto en su acto y su decir; el destino, por tanto, no le es ajeno".

\section{Referencias bibliográficas}

Alvarado, S. Botero, P. Muñoz, G y Ospina, H. 2005. "Las tramas de la subjetividad política y los..." En: Revista electrónica de Reduei. Manizales: Universidad de Manizales. Recuperado de: www.scielo.org.ar/pdf/ras/v6n11/v6n11a03.pdf

Burger, C. Burger, P. 2001. La desaparición del sujeto, una historia de la subjetividad de Montaigne a Blanchot. Madrid: Akal.

Castro, M. 2001. Del ideal y el goce. En: Lógicas de la subjetividad en la vía guerrillera y en el paso a la vida civil. Bogotá: Editorial Universidad Nacional de Colombia.

Castro, M. 2002. Investiduras, destrozos y cicatrices o del cuerpo en la guerra. En: Desde el Jardín de Freud Revista de psicoanálisis. (2) 38-45.

Castro, M. 2005. El teatro de la guerra: Una puesta en escena del sujeto. En: Desde el Jardín de Freud Revista de psicoanálisis. (5) 304-314.

Clausewitz, K. 2002. De la guerra. Recuperado de http://lahaine.org/amauta/b2-img/ Clausewitz\%20Karl\%20von\%20-\%20De\%20la\%2oguerra.pdf.

Chaparro, A. 2005. "Procesos de subjetivación, conflicto armado y construcción del Estado nación en Colombia”. En: Revista Socio - Jurídicos Vol. 7.

Chaves, G. 2005. Preguntar al psicoanálisis por la responsabilidad del sujeto. En: Desde el Jardín de Freud Revista de psicoanálisis. (5) 286-303.

Díaz, C. 2002. El sujeto en psicoanálisis. Bogotá: Universidad Nacional de Colombia.

Díaz, E. 2005. La Filosofía de Michel Focault. Buenos Aires: Biblos. 
Dunant, H. 1982. Recuerdo de Solferino. Ginebra: Comité Internacional de la Cruz Roja.

Fojón, J. 2006. Vigencia y limitaciones de la guerra de cuarta generación. En: Real Instituto Elcano de Estudios Internacionales y Estratégicos. 1-6.

Gerez, A. 1999. Imperativos del Super Yo. Testimonios clínicos. Buenos Aires: Editorial Lugar Impresiones Sud América.

González , L. 1999. Sujeto y Subjetividad. Buenos Aires: De Entre Ríos.

Grave. V. 2000. Espíritu de cuerpo. Bogotá. Editorial Planeta.

Heidegger, M. 2000. Nietzsche. Madrid: Destino.

Jaramillo, B. 2005. Consentimiento responsabilidad y culpa. Aspectos subjetivos de la violencia conyugal. En: Desde el Jardín de Freud Revista de psicoanálisis. (5) 274-285.

Lara, L. 2010. Potencial de las narrativas en la investigación de subjetividades de las y los jóvenes desvinculados de los grupos alzados en armas, en su proceso de integración a la vida civil. Magis, Revista Internacional de Investigación en Educación, $2(4), 357-370$.

Leongómez, P. 1990. La insurgencia armada: raices y perspectivas. Bogotá: Editorial Tercer Mundo.

Lugo, V. \& Pinilla, V. 2007. Matriz de análisis en el proyecto: Narrativas sobre el conflicto socio-político y cultural desde las y los jóvenes en contextos locales de Colombia (Investigación no publicada). Universidad de Manizales - Cinde, Manizales, Colombia

Muñoz, G. 2007. "Identidades o subjetividades en Construcción”. En: Revista de Ciencias Humanas. Vol. 37. Pp. 69-90.

Nasio, J. 1997. El magnífico niño del psicoanálisis, el concepto de sujeto y objeto en la teoría de Jacques Lacan. Buenos Aires: Paidós.

Observatorio de Procesos de Desarme, Desmovilización y Reintegración. 2012a. Informe. Estructuras de Autodefensas y Procesos de Paz en Colombia. Recuperado de http://www.observatorioddr.unal.edu.co/productos_academicos/ nuevos/informeestructurasdeautodefensasyprocesode\%20_pazen_colombia_ version15_02_12_final.pdf.

Observatorio de Procesos de Desarme, Desmovilización y Reintegración. 2012b. Informe. Salidas de integrantes de organizaciones guerrilleras 2002 - 2011. Recuperado de http://www.observatorioddr.unal.edu.co/pdfs/ODDR_Salidas.pdf. 
Observatorio de Procesos de Desarme, Desmovilización y Reintegración. 2011. Informe. Salidas individuales de integrantes de las Autodefensas 2003 - 2007. Recuperado de http://www.observatorioddr.unal.edu.co/productos_academicos/ nuevos/Salidas_individuales_autodefensas2003-2007.pdf.

Pécaut, D. 2003. La incertidumbre militar. El Tiempo. Recuperado de http://www. eltiempo.com/archivo/documento/MAM-1039006.

Pereña, F. 2005. Culpa y responsabilidad. En: Desde el Jardín de Freud Revista de psicoanálisis. (5) 116-127.

Pommier, G. 2002. Los cuerpos angélicos de la postmodernidad. Buenos Aires: Nueva visión.

Sánchez, G. 1999. De las armas a la política. Bogotá: T.M Editores.

Villaraga, S. 2006. La reinserción en Colombia. Experiencias, crisis humanitarias y políticas públicas. Bogotá: Fundación Cultura Democrática.

Zawady, M. 2005. La responsabilidad subjetiva, actualidad del pensamiento freudiano. En: Desde el jardín de Freud Revista de psicoanálisis. (5) 128-143. 